\title{
Jingdezhen Ceramic "Old" Brand Decorative Design Again
}

\author{
Yuchuan Guo1, Yuanyuan Fan² \\ ${ }^{1}$ University of Jingdezhen ceramic art institute of design, 333403, China \\ ${ }^{2}$ Tsinghua university academy of fine arts, 100084, China
}

Keywords: Jingdezhen porcelain, "old", the brand and design.

\begin{abstract}
Because of the porcelain products by materials, structure, the limitation of the production process itself, the partial products model has relatively perfect and fixed, not suitable for frequently change its basic model, but with the passage of time, the product style will slowly fall behind, work hard in the surface decoration pattern can solve this contradiction. Based on the same modelling style diverse design can make the classic model of these outstanding, coruscate glorious new life constantly, enduring, and meet the different needs of consumers.
\end{abstract}

\section{Introduction}

Jingdezhen ceramic decoration techniques in ancestors continuously explore and expand continuously, on the basis of later generations has obtained the full of beautiful things in eyes, each has its own characteristics. Throughout history, jingdezhen porcelain decorative techniques mainly include the decoration pattern, texture, color, etc. In terms of decoration pattern, the adornment of the jingdezhen porcelain product content is rich, most of the continuation of traditional decoration pattern is given priority to, but there are some traditional lines directly grafting to the problems in the different formative daily-used porcelain, lead to decoration pattern matching with porcelain modelling of some problems such as list, stack, simple repetition, causing some porcelain decoration pattern and the matching of the shape. All in all, jingdezhen porcelain products too traditional decoration pattern, pattern lack the sense of modern design, dealing with such problems as not enough artistic patterns. In jingdezhen porcelain product texture, texture drab problems, the art of jingdezhen porcelain is very famous and relative to the daily porcelain, artistic porcelain texture decorative use more, and most of jingdezhen porcelain with "white as jade, thin as paper, bright as a mirror, sound like Qing" to focus, so that the skin texture rarely used in household porcelain products, and can not only enrich porcelain texture decoration decorative effect, but also can produce some products with natural characteristics, rich the milk of human kindness. In reagent of porcelain, jingdezhen pattern is drawn in color material as the main decorative effect, such as blue, pastel, ancient color, colorful, color new colors, youligong, etc. And some of the glaze in the application of porcelain in the minority, jingdezhen is rich in glaze, glaze can produce colorful effects, some of the effect of the glaze as plant flowers, some such as rosy clouds of the sky. The application of glaze to not only make the jingdezhen porcelain in the porcelain products more artistic, more will cause the jingdezhen porcelain features and personality.

\section{Decorative patterns of innovation}

Jingdezhen porcelain decoration pattern mainly by the traditional pattern of product design for decoration, traditional Chinese decorative grain type is highly abstract art design, art form sense is very strong, is easy to be combined with the modelling of porcelain products. Traditional decoration pattern is the valuable wealth that history left us, the representative of Chinese traditional culture and the testimony of historical development, most traditional grain contains implication such as safe, pleasant, blessing, riches and honour, auspicious culture in conformity with the psychological needs of the Chinese people, and art spirit in the tradition of Chinese nation characteristic.

Traditional and modern is a kind of harmony and unity of opposites relations, harmony is in the modern history traces and continuation, is opposing ideas and time, jingdezhen porcelain product 
design embellished with traditional lines as the main content, is undoubtedly for the expansion and continuity of history, no matter from the aspects of process or adornment theme, is developed on the basis of the history. About the tradition, it seems far away yet close at hand, from time to space, it happened in distant past, and in contemporary it into in our life. So treat traditional we should stand in the modern tradition of position to wait and see. We should not put all your focus in the traditional. Jingdezhen porcelain product design will be simple in the design of the traditional decoration pattern of transplanted into contemporary porcelain, though, is to the continuation of traditional and spread.

\section{Decoration pattern innovation methods}

Due to the jingdezhen porcelain decoration pattern most of the products is the continuation of traditional pattern, and even the application of traditional decoration pattern is not designed to modern porcelain products, create derivative results, eventually led to the product of porcelain decoration pattern and shape matching is harmonious, this way make products not only popular with consumers, also caused the waste of resources. And jingdezhen porcelain products should be on the basis of inheriting the traditional decoration pattern of innovation, the method includes the following: the grain appearance to break up with the combination, the tedious moral pattern concise, the skilful use of patterns and forms of art decoration processing methods.

1) the decomposition and reconstruction

Will traditional pattern decomposition, and then deep observation analysis of original structure characteristics, analysis of the inner beauty things, extracted by breaking down the traditional structure composition, element of the design aesthetic. Get back together, has a new image of the traditional meaning. The prototype scattered, free decomposition, element selection model, to acquire new graphics. This decomposition combination, can get new breakthrough the traditional pattern (as shown in figure 1).

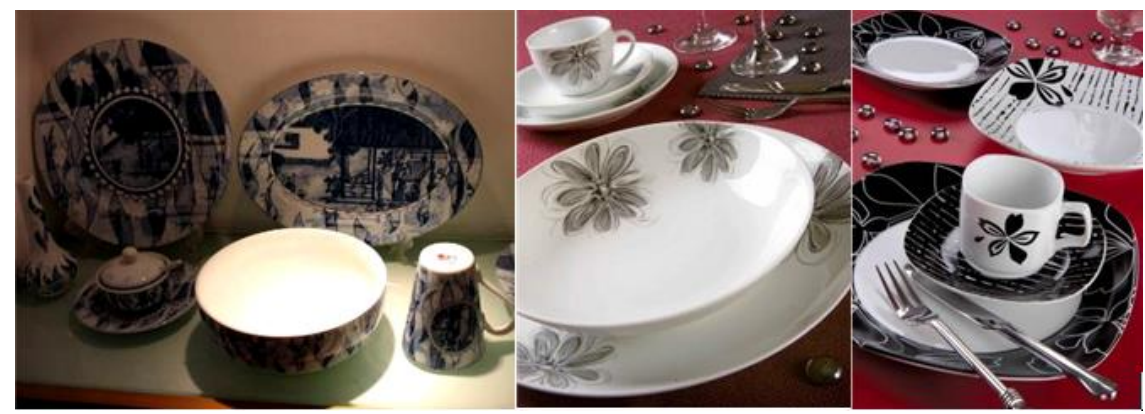

Figure 1. New breakthrough the traditional pattern

2) delete numerous take brief

Chinese traditional pattern has representational and abstract both types, each type of design is standardization, unity, logic, and complexity. But the complexity of the traditional pattern design, difficult to fast information transmission, so traditional pattern as a modern design should be delete numerous for brief, in order to convey information quickly. (as shown in figure 2)

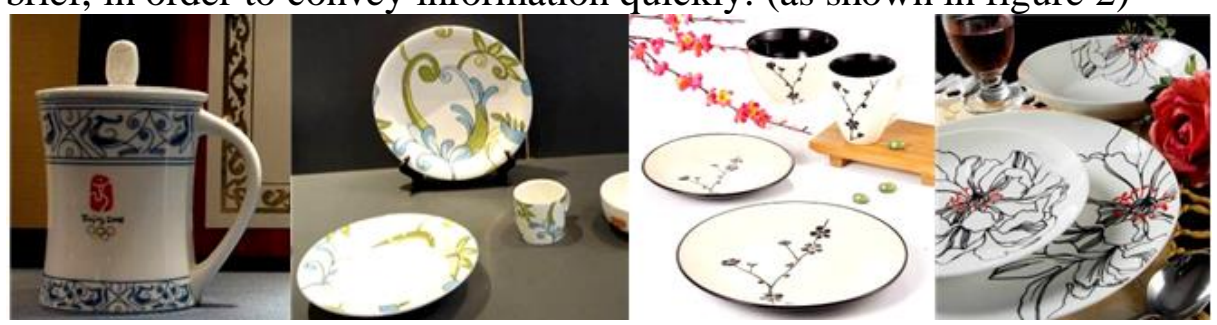

Figure 2. Delete numerous take brief

3) take its implication

Chinese traditional pattern is a diagram will be intentionally, decorative performance often to animals and plants as a subject, each graph symbolic meaning, or "good fortune, or wealth, longevity, 
love, etc. Such as lianchi yuanyang decorative, yuanyang decorative expressed the love of passion; "Live long and proper", namely, a bat, two peach, two ancient COINS, "both" is borrowed from two pieces of ancient COINS. Chinese auspicious culture implication has been integrated into the blood stream of people, to rich implication of the traditional pattern of creative use in porcelain product design not only give people a new visual experience, the vision is to satisfy the people to the hope of a better life, reflects the essence of Chinese traditional culture. Figure 28 comb ceramics, vases, decorative pattern is derived from the traditional auspicious patterns, designers have no master mould as the original design moved to the item, but scattered, the pattern, the structure of the design and implements the form perfect unifies in together (figure 3).

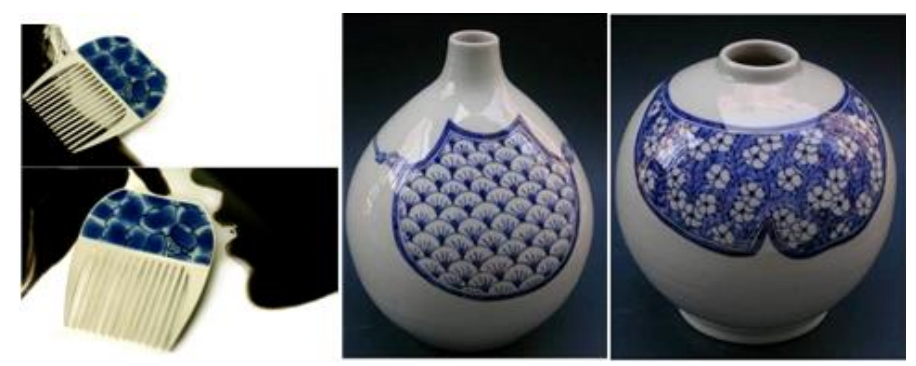

Figure 3. Structure of the design and implements the form perfect unifies in together

4) the adornment of the art form

The adornment of the porcelain product content can also draw lessons from some art very strong traditional art form. For example, Chinese painting and calligraphy art. Chinese calligraphy art is the art of line, form the different historical period different styles of calligraphy. Throughout the history of calligraphy, calligraphy letters, emotional, aesthetic artistic conception. Calligraphy is not only play the role of information transmission, but as a kind of art, it can show the vigorous, free, uninhibited, quietly elegant, profound and lasting, empty spirit, interest and detachment and so on. Calligraphy line has the rich expression ability, it can show the different style, different emotions, the adornment of the aesthetic form, using the line of calligraphy art in the porcelain products, will rich the adornment of the porcelain product content, will increase the artistic aesthetic feeling of household porcelain at the same time, meet the people of the artistic way of life. China has many forms of art, in addition to calligraphy and freehand brushwork in traditional Chinese landscape painting art, all of these can be used in household porcelain products. Because of the porcelain is the modern industrial product, has the characteristics of the rational, simple, and the performance of the art form is of great flexibility, style diversity, the application of art forms to porcelain in need to find the combining site, based on factors such as the modelling of porcelain, function, suitable for art forms processing, or simple, or take part, or design, or combination method and so on. The purpose is to make these art forms and porcelain products perfect unifies in together. Figure 4 some porcelain product design, the use of Chinese calligraphy and painting art form as a decorative content, calligraphy through artistic processing, make the products with full of artistic feeling. Chinese traditional painting in stationery, implements not only embodies the men of letters and the pursuit of artistic conception, also added a few letters quietly elegant and quiet (figure 4).

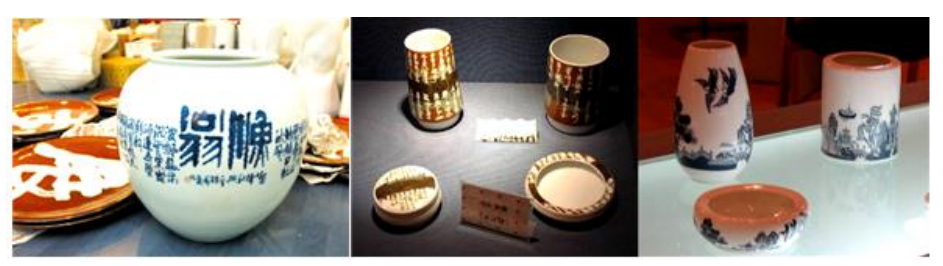

Figure 4. The adornment of the art form 


\section{Decorative pattern and the modelling of harmonious match}

As a modern porcelain product development design, shape and decoration is a whole interconnected, cannot separate apart to design, but to create a whole design concept, "even a single decal decoration design, must also consider the shape characteristic, the reference shape decoration parts and adapt to the requirements, in order to achieve unified harmony and unity of effect". Shape and decoration with suitable proportion, can make the person feel the overall harmony, like nature itself.

\section{Decorative artistic content}

Porcelain products as important furniture supplies, universal attention by the industry and consumers in recent years, with the improvement of people's aesthetic standard, decoration of personalized, art will be the development trend of porcelain products. This determines the decorative porcelain product content is not only confined to the traditional designs, but extending to the wider, for example, the application of all kinds of art forms to porcelain products. Chinese art form diversification. Wrong colour used in gold, painted carved with palace of beauty in the art; A light and refined, water lotus beauty of literati art; Have a warm deep, rapid, simple, beauty of folk art; Have xuan as sacred land, the magic of guesswork religious art of beauty. Each art contains the content is rich, have poetry, painting, arts and crafts and so on each aspect, each kind of art reflects the different artistic realm. Thus different artistic content used in porcelain produces a kind of artistic effect. Chinese freehand brushwork in traditional Chinese landscape painting, for example, it has "considerable can ju can swim" the role of the landscape painting are the sacred cows of ancient writers, because they do not want to because of desire, natural scenery and away from the king. Face landscape painting can be "no feast, sit springs of poor lives", fully guides the beauty of the natural landscape, in order to solve their aversion to worldly affairs and enjoy contradiction of fame, use the view picture instead appreciate the natural scenery.

In the same way, in the contemporary society, and improve life quality of people's living standard, the rhythm is faster, and live for a long time in the concrete jungle in cities people increasingly want to walk into nature, natural and pure and fresh and pastoral "' tori, picking life artistic conception. If the porcelain decorative content in natural landscape, the south, danya clear water, songbirds ring organ, ever-green flowers and trees, pavilions, pavilions and other natural images, people in the use of porcelain products, also can produce in downtown, and enjoy the beauty of a clean, quietly elegant, spiritually. For example, in the 2010 jingdezhen international ceramics exposition, Taiwan blue porcelain company (jingdezhen is one of its two production bases located in mainland China) porcelain products to artistic porcelain ware, modernity, was welcomed by consumers (as shown in figure 5). The products of the company puts beauty among them, the product design elements into things, ancient and modern elements, traditional and modern elements, all elements meet the demand of contemporary fashion. Method of blue porcelain design is given priority to with the flow line of western "new art", perfect blend in the east and elegant cultural temperament, outline of the nature of the flowers and plants, pest birds rhythm, wilderness is bold and unrestrained, vivid and gorgeous, in the form of three-dimensional decoration, vividly presented to the audience. Method of blue porcelain will be traditional Chinese CiYi deduce so heyday and fashion, he completely fusion between eastern and western aesthetics, form a, created a colorful "new China". Making daily-used porcelain is no longer monotonous mechanical bottle container canister, make the artistic porcelain is no longer a high antique in the museum, small exquisite furnishing articles, up gorgeous tableware or YiZhanZhan elegant tea cup, add infinite interest to our life art and fashion (figure 5).

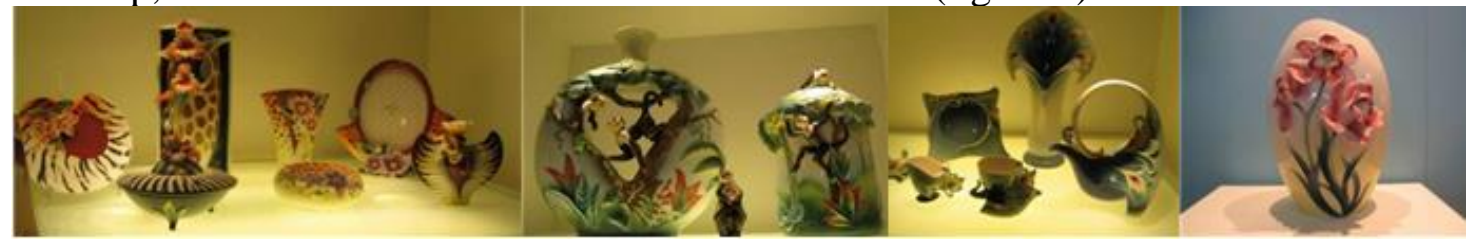

Figure 5. Artistic porcelain 


\section{Conclusion}

To sum up, jingdezhen porcelain products on the one hand, should pay attention to the market demand, according to the needs of consumers in terms of product design; Jingdezhen porcelain products, on the other hand, the design should make full use of local resources and characteristics, in the tradition and the adornment of the existing technique and process for innovations, so as to design the rich contents, various forms, novel and distinctive adornment, jingdezhen porcelain products, only in this way can the jingdezhen porcelain industry have a foothold in the market.

\section{Acknowledgments}

Jiangxi Province art science planning topics: Inheritance and brand redesign of "old brand" of Jingdezhen ceramics, YG20150101.

\section{References}

[1] Xiu mei wu: the inheritance and change - jingdezhen porcelain development research of the republic of China, Beijing, guangming daily press, 2012, 5 .

[2] Xiu mei wu: the traditional handicraft culture research - ceramic hangzhou fan, for example, Beijing: guangming daily press, 2013, 5 .

[3] Zhen fan wan, Lin Songhua editor: studies of modern times social transformation in overall, Beijing: China social sciences press, 2001.

[4] XiChuan performance: "the classical works of the design art anthology, a working: southeast university press, 2002. 